\title{
Hypermnesia for pictures and for words: The role of recall modality (pictures vs. words)
}

\author{
GABRIELE A. DRAGONE, MARGARET BROWN, ANN ROBINS KRANE \\ Mount Saint Vincent University, Halifax, Nova Scotia B3M 2J6, Canada
}

and

\author{
RICHARD V. KRANE \\ Acadia University, Wolfville, Nova Scotia BOP 1 XO, Canada
}

\begin{abstract}
Hypermnesia (an increment in recall over multiple recall attempts) typically is obtained when a to-be-remembered list is presented as pictures, but not when the list is presented as words. All previous studies have involved a verbal recall format. To evaluate the role of recall modality in producing the picture-word difference, subjects received either a picture list or a word list and were asked to recall the list two or three times (in Experiments 2 and 1, respectively) either as words or as drawings. Focusing on the dependent variable of cumulative responses per trial, all (both picture and word) groups developed hypermnesia. Recall format produced no differential effects on performance.
\end{abstract}

Recently Ebbinghaus' classic forgetting curve (illustrating amnesia as a function of time) has been challenged. Under certain conditions, hypermnesia (rather than amnesia) for a to-be-remembered list can be consistently obtained (e.g., Erdelyi \& Kleinbard, 1978). The phenomenon of hypermnesia can be traced back to investigations during the early part of this century by Ballard (1913), who used the term reminiscence. Ballard defined reminiscence as "the remembering again of the forgotten without relearning" (p. 1), which is an equally appropriate definition of hypermnesia.

More recently, Erdelyi and his colleagues have reported hypermnesia for a picture list but not for a word list (e.g., Erdelyi \& Becker, 1974), whereas Buschke (1974) has produced hypermnesia for simple nouns (usually concrete, picturable ones). Furthermore, Erdelyi, Buschke, and Finkelstein (1977) agree that while hypermnesia will be easily produced for a to-beremembered picture list, a word list may also produce hypermnesia, depending upon the cognitive strategies a subject uses in processing the to-be-remembered words. For example, Erdelyi, Finkelstein, Herrell, Miller, and Thomas (1976) found hypermnesia for a list of concrete words when subjects were instructed to use an imagery mnemonic, and Erdelyi et al. (1977) have reported hypermnesia for the answers to a list of riddles.

In an attempt to acquire more information about the conditions under which hypermnesia occurs, the present research addressed a confounding common to all the

This research was supported by a grant from the Research Committee of Mount Saint Vincent University to Ann Robins Krane. Requests for reprints should be addressed to Ann Robins Krane, Psychology Department, Mount Saint Vincent University, Halifax, Nova Scotia B3M 2J6, Canada. published studies of hypermnesia. In each of the published studies, all subjects (whether they were in a word format group or in a picture-image format group) were instructed to recall in writing on each trial (i.e., recall all items as simple words). Thus, it is possible that hypermnesia results whenever the modality used to recall a list is different from the modality used to present that list.

Erdelyi and Becker (1974) have stated that subjects would find a pictorial recall procedure to be very difficult and time-consuming. However, in a pilot study, we found that subjects had no difficulty in reproducing the simple line drawings generally used as pictorial stimuli. Thus, in two studies, subjects were presented with a 40-item to-be-remembered list of pictures or words and were instructed on several occasions to recall the items as written words or as drawings.

\section{EXPERIMENT 1}

\section{Method}

Design. The present study involved a 2 by 2 by 3 mixed factorial design with the between-subjects factors of presentation modality and recall modality and a within-subjects factor of trials; subjects were asked to recall a to-be-remembered list on three occasions.

Subjects. The study involved 32 undergraduate students from Mount Saint Vincent University, Halifax, Nova Scotia, who were fulfilling course requirements for an introductory psychology course. Subjects were randomly assigned to one of four groups: (1) a picture presentation/picture recall group, (2) a picture presentation/word recall group, (3) a word presentation/picture recall group, and (4) a word presentation/word recall group.

Materials. Forty pictures and 40 appropriate labels for simple, discrete objects (e.g., heart, horse, comb) were drawn in India ink on Kodak diffusion film and mounted as $2 \times 3$ in. slides. The 40 slides composing a list were placed at random in a Carousel and were projected using a Kodak Ektagraphic slide 
projector, with time of viewing held constant at $5 \mathrm{sec} / \mathrm{slide}$. Procedure. Initial instructions to the subjects were to attend to the series of 40 slides carefully because a memory test would be administered subsequent to viewing. Within the picture presentation condition $(n=16)$, eight subjects were instructed to recall the items by drawing them, and the other eight subjects were instructed to recall the items by printing labels for the items. The same procedure was followed for the word presentation condition $(n=16)$. Written instructions given immediately following the acquisition list were intended to reduce recency effects. A forced-recall paradigm was employed, requiring subjects to generate 40 items, guessing if necessary, within a $15-\mathrm{min}$ period, thereby holding the response criterion constant across the three trials. Subjects were advised when every 3 rd minute had lapsed during each 15 -min recall period. This procedure was followed through the three recall attempts, with subjects' protocols collected prior to distribution of the response sheets for each subsequent trial. Subjects were encouraged to increase their recall from the prior trial.

\section{Results}

One 2 by 2 by 3 analysis of variance involving the between-subjects variables of presentation modality and recall modality and the within-subjects variable of trials was performed on the cumulative number of items recalled per trial. A second 2 by 2 by 3 analysis was performed on the simple number of items recalled per trial. As the two analyses produced comparable results, only the data from the more sensitive measure of recall (i.e., cumulative recall per trial) will be reported. This analysis revealed statistically significant main effects of presentation modality $[\mathrm{F}(1,28)=17.52, \mathrm{p}<.001]$ and of trials $[F(2,56)=71.17, p<.001]$. The other main effect and the interaction effects did not reach statistical significance. As Table 1 shows, the main effect of presentation modality indicates an overall superiority of recall by subjects in the picture presentation condition (mean = 27.4) compared with subjects in the word presentation condition (mean $=22.2$ ). The mean cumulative number of items recalled on Trials 1,2 , and 3 were 22.2, 25.4, and 26.8 , respectively. Inspection of Table 1 also shows that each of the four groups exhibited hypermnesia.

Consistent with published studies, these data provide evidence of a hypermnesic effect for pictures and for words over three recall trials, as well as for the superior recall of pictures relative to that of words. On the other hand, contrary to the hypothesis under investigation, the development of hypermnesia did not require that the

Table 1

Experiment 1: Mean Cumulative Number of Items Recalled per Trial as a Function of Presentation Modality and Recall Modality

\begin{tabular}{llllcc}
\hline \multicolumn{2}{c}{ Experimental Condition } & & & \multicolumn{3}{c}{ Trial } \\
\cline { 1 - 1 } \cline { 5 - 7 } \multicolumn{1}{c}{ Presentation } & Recall & & 1 & 2 & 3 \\
\hline Picture & Picture & 25.1 & 28.9 & 29.9 \\
Picture & Word & & 24.6 & 27.2 & 28.9 \\
Means for Picture Presentation & & & 24.9 & 28.1 & 29.4 \\
Word & Picture & 19.0 & 23.0 & 24.0 \\
Word & Word & & 20.1 & 22.6 & 24.4 \\
Means for Word Presentation & & & 19.6 & 22.8 & 24.2 \\
\hline
\end{tabular}

modality for recalling a list be different from the modality used to present the list.

\section{EXPERIMENT 2}

The second experiment was undertaken primarily to assess the reliability of the first experiment, given slight modifications. Experiment 2 involved 40 participants from the same institution, who were tested in small groups, not exceeding 5 in number. As an added incentive, subjects were assured of bonus points toward their course mark in exchange for participation in the present study.

\section{Method}

Utilizing the same slides as the stimuli, the design of Experiment 1 was used with the following adjustments: (1) Two lists for pictorial presentation and two lists for word presentation were constructed to insure the results were generalizable, (2) instead of three recall trials, only two trials were administered, based on the finding in Experiment 1 that two trials were sufficient to generate a hypermnesic effect, and (3) a Singer Caramate was used to present the stimuli. In all other respects, Experiment 2 replicated Experiment 1.

\section{Results}

Utilizing the same method of analysis as in Experiment 1 , significance was obtained for a main effect of presentation modality $[\mathrm{F}(1,36)=15.85, \mathrm{p}<.001]$ and of trials $[F(1,36)=98.74, p<.001]$. Again, the other main effect and the interaction effects did not reach statistical significance. The main effect of presentation modality indicates an overall superiority of recall by subjects in the picture presentation condition compared with subjects in the word presentation condition. Inspection of Table 2 shows that the means for picture presentation and word presentation were 27.2 and 21.2 , respectively. Consistent with the hypermnesia phenomenon, the cumulative means associated with the trials variable were 23.0 for Trial 1 and 25.4 for Trial 2. Moreover, hypermnesia was obtained for to-be-remembered words as well as for pictures.

\section{GENERAL DISCUSSION}

The results of these two experiments not only lend support to the hypermnesic phenomenon, they also answer the question

Table 2

Experiment 2: Mean Cumulative Number of Items Recalled per Trial as a Function of Presentation Modality and Recall Modality

\begin{tabular}{lllll}
\hline \multicolumn{2}{c}{ Experimental Condition } & & & \multicolumn{2}{c}{ Trial } \\
\cline { 5 - 6 } \multicolumn{1}{c}{ Presentation } & Recall & & 1 & 2 \\
\hline Picture & Picture & & 26.1 & 28.6 \\
Picture & Word & & 25.6 & 28.5 \\
Means for Picture Presentation & & & 25.8 & 28.5 \\
Word & Picture & & 19.4 & 22.1 \\
Word & Word & & 20.8 & 22.3 \\
Means for Word Presentation & & & 20.1 & 22.2 \\
\hline
\end{tabular}


the study was designed to examine, that is, does hypermnesia occur only when the modality of output is changed? Clearly, recall modality has no significant impact on the development of hypermnesia.

\section{REFERENCES}

BAlla RD, P. B. Oblivescence and reminiscence. British Journal of Psychology Monograph Supplements, 1913, 1(Whole No. 2). Buschke, H. Spontaneous remembering after recall failure. Science, 1974, 184, 579-581.

ERdelyi, M. H., \& BeckeR, J. Hypermnesia for pictures: Incremental memory for pictures but not words in multiple recall trials. Cognitive Psychology, 1974, 6, 159-171.
Erdelyi, M. H., Buschke, H., \& Finkelstein, S. Hypermnesia for Socratic stimuli: Growth of recall for an internally generated memory list abstracted from a series of riddles. Memory \& Cognition, 1977, 5, 283-286.

Erdelyi, M. H., Finkelstein, S., Herrell, N., Miller, B., \& Tномаs, J. Coding modality vs. input modality in hypermnesia: Is a rose a rose a rose. Cognition, 1976, 4, 311-319.

ERdelyi, M. H., \& KleinBard, J. Has Ebbinghaus decayed with time? The growth of recall (hypermnesia) over days. Journal of Experimental Psychology: Human Learning and Memory, 1978, 4, 275-289.

(Received for publication July 28, 1980.) 